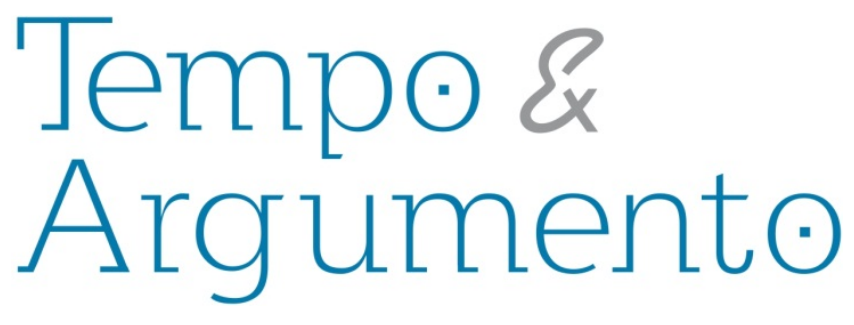

\title{
Civismo e cidadania num regime de exceção: as políticas de formação do cidadão na ditadura civil-militar (1964 - 1985) ${ }^{1}$
}

\begin{abstract}
Resumo
Este artigo é dedicado à ação dos intelectuais reunidos no Conselho Federal de Cultura no Ministério da Educação e Cultura durante a ditadura civil-militar (1964-1985). Busca investigar a construção de políticas culturais e educacionais destinadas à formação do cidadão considerado ideal. Os intelectuais do MEC estavam empenhados na defesa do civismo, corrente de pensamento que atravessou os setores estatais responsáveis pelo direcionamento de políticas culturais e educacionais na ditadura civil-militar. Serão analisados os Cadernos de Estudos Brasileiros, produção resultante do "Curso de Atualização de Estudo dos Problemas Brasileiros", e duas obras com expressiva participação de intelectuais atuantes no MEC: o Atlas Cultural do Brasil, publicado pela Fundação Nacional do Material Escolar, Fename, em 1972, e O cidadão e o civismo: educação moral e cívica, suas finalidades, organizada pelo CONSELHO FEDERAL DE CULTURA por Adonias Aguiar Filho, e publicada pela Comissão Nacional de Moral e Civismo (CNMC) em 1982.Tais publicações expressam a compreensão dos intelectuais que atuavam no Estado sobre os elementos formadores do civismo e sobre o papel do cidadão num regime de exceção.
\end{abstract}

Palavras-chave: Intelectuais. Civismo. Ensino.

\author{
Tatyana de Amaral Maia \\ Doutora em História pela \\ Universidade do Estado do Rio de \\ Janeiro. Professora adjunta da \\ Universidade Severino Sombra. \\ tatyanamaia@yahoo.com.br
}

\footnotetext{
Para citar este artigo:

MAIA, Tatyana de Amaral. Civismo e cidadania num regime de exceção: as políticas de formação do cidadão na ditadura civil-militar (1964 - 1985). Revista Tempo e Argumento, Florianópolis, v. 5 , n.10, jul./dez. 2013. p. $182-206$.
}

\section{DOI: $10.5965 / 2175180305102013182$}

http://dx.doi.org/10.5965/2175180305102013182

\footnotetext{
${ }^{1}$ Este artigo é financiado pelo Programa Jovem Cientista Nosso Estado/FAPERJ (2012-2015).
} 


\title{
Civics and citizenship in a regime of exception: training policies of the citizen in civil-military dictatorship
}

\begin{abstract}
This article is dedicated to the action of intellectuals in the Conselho Federal de Cultural at the Ministério da Educação e Cultura during the civil-military dictatorship (1964-1985). Seeks to investigate the construction of cultural and educational policies aimed at training the citizen considered ideal. The intellectuals of the MEC were engaged in the defense of civility, stream of thought that has crossed the state sectors responsible for directing cultural and educational policies in civil-military dictatorship. We will analyze "Cadernos de Estudos Brasileiros", the resulting production of "Curso de Atualização de Estudo dos Problemas Brasileiros " and two works with significant participation of intellectuals working in the MEC: "Atlas Cultural do Brasil", published by the Fundação Nacional do Material Escolar, FENAME, in 1972, and, "O cidadão e o civismo: educação moral e cívica, suas finalidades", organized by Adonias Aguiar Filho and published by the Comissão Nacional de Moral e Civismo (CNMC) in 1982. These publications express understanding of intellectuals working in the state on the formative elements of civics and the role of citizens in a exception.
\end{abstract}

Keywords: Intellectuals. Civism. Instruction. 
As recentes pesquisas sobre o período de 1964 a 1985 têm destacado a presença dos grupos civis, institucionalizados ou não, na construção do Estado ditatorial brasileiro. Tais investigações contrastam com as memórias construídas logo após início do processo de abertura, segundo as quais o regime instalado após o golpe de 1964 era exclusivamente militar, rompendo com explicações de simples dicotomias. Assim, essa historiografia tem investigado a participação dos civis no golpe, na montagem e na consolidação do Estado ditatorial brasileiro (1964-1985), a partir de relações de ambivalências, silêncios e consensos, tão importantes quanto a repressão e o terror na manutenção do regime.

O objetivo deste artigo é investigar a participação dos intelectuais na construção do discurso cívico. O civismo foi o ideário por excelência de legitimação do Estado derivado do golpe de 1964. Serão analisados os Cadernos de Estudos Brasileiros, produção resultante do "Curso de Atualização de Estudo dos Problemas Brasileiros", destinado à formação de professores, e duas obras com expressiva participação de intelectuais atuantes no MEC: o Atlas Cultural do Brasil, publicado pela Fundação Nacional do Material Escolar, Fename, em 1972, e O cidadão e o civismo: educação moral e cívica, suas finalidades, organizada por Adonias Aguiar Filho, publicada pela Comissão Nacional de Moral e Civismo (CNMC) em 1982.

A partir de 2000, com a publicação do livro Ditadura militar, esquerdas e sociedade, de Daniel Aarão Reis, as pesquisas tomaram um novo impulso e incorporaram às suas análises as complexas relações estabelecidas entre civis e militares naqueles tortuosos anos. Nesta perspectiva, a ditadura não seria exclusivamente militar, fruto da truculência e do autoritarismo gestados na caserna e impostos a toda a sociedade a partir de 1964 . Ao contrário, diversos setores da sociedade civil aplaudiram o golpe que derrubou o presidente João Goulart; promoveram manifestações entusiásticas em favor da intervenção militar e ingressaram nas fileiras estatais para propor projetos de desenvolvimento para a nação. É neste sentido que o artigo incorpora a perspectiva de que se trata de um regime civil-militar. A ditadura, composta e legitimada também pela participação de civis, se guiou por projetos gestados por estes antes mesmo do golpe de 1964. Durante o processo de redemocratização, iniciado em 1974, elaborou-se uma 
memória de resistência que apresenta os civis como defensores incontestes da democracia, mas se silenciaram as relações de apoio, participação e legitimidade de vários setores da sociedade durante os 21 anos do regime.

A tese de doutorado de Lúcia Grinberg, publicada em 2009, Partido Político ou Bode expiatório: um estudo sobre a Aliança Renovadora Nacional (Arena), 1965-1979, trouxe uma importante contribuição para os estudos dedicados à participação dos civis no regime. Ao investigar os integrantes da Arena, a autora desmistifica a tese corrente no meio acadêmico de que esse partido representava os interesses da extinta UDN. De fato, era formada por políticos oriundos tanto da UDN quanto do PSD, mas que transitavam pelos cargos do executivo desde o primeiro Governo Vargas (1930-1945). Segundo Grinberg (2009, p. 27), a principal característica da Arena era a de ser um "partido ligado ao Estado". Essa permanência dos atores políticos presentes na cena pública desde os anos 1930 reforça a percepção de que o regime fundado após o golpe de 1964, apesar das especificidades do período, contou com a intensa participação dos civis há muito engajados na orientação do Estado brasileiro.

Outra obra que merece destaque é Direitas em movimento: a campanha da mulher pela democracia e ditadura no Brasil, de Janaína Cordeiro, fruto de sua dissertação de mestrado, publicada também em 2009. A historiadora dedica-se ao estudo da Campanha da Mulher pela Democracia (Camde), criada em 1962, cujo produto mais notável foi a Marcha da Vitória, no Rio de Janeiro, dois dias após o golpe. A marcha realizada pela Camde foi equivalente às marchas que mobilizavam milhares de pessoas na capital paulista e outras cidades do País. Após o golpe, a Camde, para Cordeiro (2009, p.15), assim como outras organizações cívicas surgidas em oposição ao governo João Goulart, manteve-se atuante e saiu em defesa da intervenção militar, necessária diante daquilo que se considerava uma crescente ameaça comunista: a intensa mobilização social pelas reformas de base que eclodiram nos anos de 1960. Ao estudar a campanha, Janaína Cordeiro lançou luz sobre o apoio civil ao golpe de 1964 e ao regime, revisitando uma memória construída exclusivamente sobre a resistência civil ao regime.

Por fim, a coleção A construção Social dos Regimes Autoritários, publicada em 2010, em três volumes, organizada pelas historiadoras Denise Rollemberg e Samantha Quadrat 
Vaz, dedica o segundo volume à análise dos governos ditatoriais contemporâneos no Brasil e na América Latina. As organizadoras, ao incorporar os conceitos de "zona cinzenta" e "pensar-duplo", elaborados por Pierre Laborie, selecionaram pesquisas dedicadas à ação de personagens que se situavam nesses espaços nebulosos de apoio aos regimes ditatoriais. Para Rollemberg e Quadrat (2010, p. 14), tal ação foi marcada também por estratégias de silêncio, consentimento e legitimidade. Essas relações só foram possíveis graças ao espaço intermediário existente na rígida polarização que subdivide a sociedade entre os que apoiavam e/ou condenavam o regime. A esse espaço social, Pierre Laborie (2010, p. 31) chamou de "zona cinzenta". Trata-se de uma relação altamente instável. Os atores que transitam nesta "zona" estão marcados por ações ambivalentes, características do pensar-duplo, ou seja, constroem situações simultâneas de proximidade e distanciamento de acordo com as circunstâncias históricas do momento.

Este artigo se alinha a essas pesquisas, dedicadas à compreensão dos lugares de construção de consenso e legitimidade da ditadura. Pretende contribuir com os estudos dedicados à participação de civis ao longo do regime, portanto, para além do apoio público ao episódio do golpe de 1964. Para isso, busca compreender a ação dos intelectuais no Ministério da Educação e Cultura durante a ditadura civil-militar (19641985), particularmente na construção de políticas culturais e educacionais que pudessem contribuir para formar o cidadão considerado ideal.

A percepção teórica da ambivalência na relação estabelecida entre civis e militares pode ser duplamente exemplificada no caso dos intelectuais que atuaram no MEC e foram responsáveis pela difusão do civismo através da publicação de obras e da realização de cursos de formação, seja por lançar luz sobre as tensões provocadas por ações do executivo, especialmente no caso da censura, seja apoiando o regime, posição possível justamente pela permanência de posicionamentos críticos, ainda que moderados, sobre as intervenções consideradas excessivamente arbitrárias. As "resistências" a algumas ações de outros setores do Estado buscavam gerar mecanismos de conciliação e reorganização do regime, sem, contudo, contestar a sua legitimidade. 


\section{A construção e o uso do civismo na ditadura civil-militar}

A construção do ideário cívico não foi exclusividade dos intelectuais, militares ou grupos políticos integrados ao Estado durante o período da ditadura civil-militar. Desde a

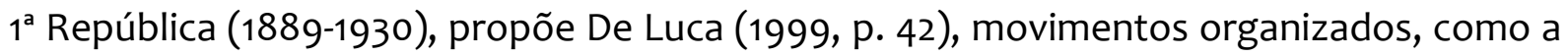
Liga da Defesa Nacional, fundada por Olavo Bilac, em 1915, já expressavam a presença desse ideário no pensamento político e social brasileiro, ainda que aparecesse de forma intermitente. Aliás, Olavo Bilac tornou-se uma personagem-símbolo do civismo nos anos de chumbo, sendo reverenciado como exemplo de cidadão consciente de seus deveres perante sua comunidade. A historiadora Angela de Castro Gomes (2009, p. 3) destaca a construção de uma "cultura cívico-patriótica" pelos republicanos desde o final do século XIX, processo associado à formulação de uma "história pátria" considerada fundamental na formação dos cidadãos após a proclamação da República. Para Gomes, a necessidade dos republicanos de elaborar um novo discurso político, capaz de forjar os elementos simbólicos da nação, os levará a buscar na história e na geografia nacionais os artefatos necessários à consolidação de um ideário cívico para gerar o “sentimento patriótico" em todos os brasileiros.

Acreditamos que os discursos construídos em torno do civismo ao longo da ditadura civil-militar apresentam especificidades próprias, com usos muitas vezes distintos dos períodos anteriores ao golpe. Esta declaração inicial não restringe a promoção do ideal cívico ao setor cultural do MEC; ao contrário, observamos que a noção de civismo presente nos discursos aqui analisados está apoiada também na ação de outros setores governamentais.

O civismo, ideário-chave durante a ditadura civil-militar, foi incorporado aos discursos e às ações políticas dos intelectuais atuantes no MEC através da associação do civismo, ideário político por excelência, à noção de cultura. Como propõe Maia (2012, p. 35), o papel da cultura seria realçar os elementos que compõem a nação, realçando uma visão otimista sobre a sociedade brasileira. A defesa de um tipo de cultura, a nacional, foi considerada fundamental para a formação de cidadãos conscientes tanto de seu papel de devoção à pátria quanto da necessidade de solidariedade social. Assim, enquanto nas 
escolas as disciplinas história, geografia e literatura nacionais eram fundamentais à encenação da trajetória histórica de formação da nação, no setor cultural, o papel caberia aos monumentos, às comemorações públicas de efemérides, aos conjuntos arquitetônicos, às manifestações folclóricas, etc.

A incorporação da visão otimista pelo Estado brasileiro tem origem no primeiro governo Vargas (1930-1945), através da sua associação às correntes nacionalistas conservadoras. Contudo, na ditadura civil-militar, o otimismo trazia consigo a perspectiva de um futuro próspero, gestado por um passado nacional cuidadosamente reinventado.

Pode-se dizer que, durante o Estado Novo, a assim chamada "identidade brasileira" seria amplamente redefinida - pelo menos do ponto de vista governamental. Muitos dos elementos que posteriormente, durante a ditadura militar pós-64, seriam utilizados pela propaganda política foram estabelecidos nessa época: a valorização do trabalho, uma certa ideia de nação - baseada nos princípios de coesão e cooperação. Pode-se dizer, então, que essas são matizes ideológicas do Estado Novo e que seriam retrabalhadas na ditadura militar (FICO, 1997, p. 34).

A corrente otimista "reinventada" na ditadura civil-militar garantiu o substrato ideológico ao civismo, sustentando-o através da produção simbólica elaborada pelos diversos agentes e agências atuantes na ditadura.

As ideias-força de tradição, brasilidade, mestiçagem, país continental, pluralidade cultural, associadas à leitura desenvolvimentista de um futuro glorioso, capitalista e ocidental produzida pelo discurso otimista, foram incorporadas ao discurso cívico. Considero que o civismo é a exacerbação desse otimismo, possibilitando uma sistematização conceitual até então difusa. O civismo, ao incorporar o otimismo, organizou o aparato discursivo e ideológico nacionalista-conservador em torno do projeto autoritário dos governos militares. O civismo, neste caso, sobrepõe-se à cidadania moderna por desconsiderar a legitimidade dos interesses políticos conflitantes existentes na sociedade; por limitar a capacidade de organização política coletiva; por aviltar a liberdade de expressão e os direitos individuais em nome de supostos valores nacionais superiores. A defesa desses valores superiores absolutos, por princípio imutáveis e responsáveis pela existência da sociedade, legitimava ações coercitivas que limitavam a liberdade individual, esta última sacrificada em nome de um bem considerado maior que 
os cidadãos: a Nação. Aliás, a função social do cidadão estava bem definida: ele era o agente responsável pela proteção desses valores; ao romper com esse dever, perdia também seus direitos políticos e sociais, ou seja, deixava de ser cidadão; tornava-se um subversivo.

A relação entre o cidadão e a sociedade civil, estabelecida através do processo de conscientização cívica, pressupunha a participação ativa desse patriota na condução dos destinos da nação, atribuindo-lhe como dever máximo a defesa dos valores superiores diante das ameaças provocadas pelas mudanças sociais. As inevitáveis transformações vivenciadas pelas sociedades modernas traziam em seu bojo riscos para a unidade nacional e o funcionamento ordeiro da sociedade brasileira - ambos os fatores fundamentados na tradição nacional. Para resguardar a nação dos possíveis sobressaltos provocados pelas mudanças sociais que poderiam produzir abalos nas estruturas formadoras da sociedade, devido ao seu alto grau de imprevisibilidade, caberia aos cidadãos identificar os perigos de novas ideias protegendo os valores superiores absolutos - valores cívicos e éticos. Ao preservá-los de todas as transformações conjunturais, as estruturas sociais permaneceriam inabaladas e as mudanças sociais trariam consigo somente os possíveis benefícios do processo de modernização, sem ameaçar a sociedade. Dessa forma, o cidadão era o agente social responsável por excelência pela preservação da nação.

O papel do ensino, em todos os níveis, na construção de uma consciência cívica associada ao valor da tradição, apareceu nos documentos oficiais da Comissão Nacional de Moral e Civismo, do Conselho Federal de Educação (CFE), do Conselho Federal de Cultura e, claro, nos discursos dos ministros da Educação e Cultura. Como propõe Gomes (2009, p. 1), desde a $1^{\text {a }}$ República, elaborou-se uma "pedagogia da nacionalidade", necessária à "consolidação de uma cultura política republicana”. Na ditadura civil-militar, a tarefa caberia às disciplinas “Educação Moral e Cívica”, no ensino básico, e ao "Estudo dos Problemas Brasileiros", no ensino superior.

Em 1969, foi promulgado o Decreto-Lei n. 869, de 12 de setembro de 1969, dispondo sobre a obrigatoriedade do sistema de ensino de ofertar a disciplina "Educação Moral e Cívica”. O mesmo decreto, artigos n. 5 e n. 6, criou a Comissão Nacional de Moral 
e Civismo, CNMC, no ensino básico, e "Estudo dos Problemas Brasileiros", no nível superior. $\mathrm{O}$ artigo $\mathrm{n} .2$ do referido decreto destacava que às disciplinas cabia:

O aprimoramento do caráter, com o apoio moral, na dedicação à comunidade e à família, buscando-se o fortalecimento desta como o núcleo natural e fundamental da sociedade, a preparação para o casamento e a preservação do vínculo que a constitui (BRASIL; 1969, p.1).

A falta de um curso superior capaz de formar os professores para ministrar as disciplinas "Educação Moral e Cívica” e “Estudo dos Problemas Brasileiros" levou a Universidade Federal do Rio de Janeiro, entre 1971 e 1980, através do Fórum de Ciência e Cultura, a promover o "Curso de Atualização sobre Problemas Brasileiros", destinado à capacitação de docentes de ensino superior para ministrara disciplina Estudo dos Problemas Brasileiros. Foi proposto por Pedro Calmon, então membro do Conselho Federal de Cultura, como solução provisória à inexistência desse curso em nível superior. Organizado em conferências temáticas, foi ministrado por intelectuais vinculados ao MEC, ministros de Estado e oficiais militares do alto escalão do governo federal. Intelectuais atuantes no Conselho Federal de Cultura, como Afonso Arinos de Mello Franco, Arthur Cézar Ferreira Reis, Clarival do Prado Valladares, Djacir Menezes, Gilberto Freyre, José Candido de Melo Carvalho, Manuel Diégues Júnior, Raymundo Moniz de Aragão e Pedro Calmon proferiram conferências nos cursos pelo tempo que duraram. A coordenação coube ao ex-ministro da Educação, Raymundo Moniz de Aragão. As conferências foram integralmente publicadas nos "Cadernos de Estudos Brasileiros", editados pela UFRJ, entre 1972 e 1980. No primeiro ano, do curso foram realizadas 34 conferências temáticas e diplomados 65 professores do nível superior. O editorial do primeiro número do periódico “Cadernos de Estudos Brasileiros”, em 1972, assinado pelo reitor da UFRJ, Djacir Menezes, e reproduzido integralmente em todos os seus 20 números, destacava a importância de conscientizar as elites intelectuais brasileiras sobre os desafios nacionais:

Os responsáveis pelo programa, que poderíamos chamar de 'atualização' da consciência das elites estudiosas a respeito de nossos problemas, promovido por órgão superior de cultura universitária, têm a íntima convicção de que trabalham em prol da consolidação institucional do Brasil (MENEZES, 1972, p.1). 
O investimento dos principais membros do CFC neste projeto caracteriza a preocupação e a participação desses intelectuais na difusão do civismo através do uso político da cultura. Sua constante presença no "Curso de Atualização dos Problemas Brasileiros", inclusive em sua elaboração e organização, demonstra seu empenho em propagar o civismo como pilar de sustentação da nacionalidade e, principalmente, da associação entre civismo e cultura nacional.

O curso, oferecido anualmente, era organizado através de conferências. O objetivo divergia dos tradicionais cursos de formação. Não previa nenhum tipo de avaliação ou disciplina específica. A opção metodológica de sua organização - realização de conferências - tinha como intenção promover uma atualização dos futuros professores das duas referidas disciplinas, apresentando uma série de assuntos considerados fundamentais para o desenvolvimento da nação e manutenção da segurança nacional. A coleção Cadernos de Estudos Brasileiros registrou os títulos das conferências ministradas nos anos de 1971, 1972 e 1974. Cada edição oferecia 34 conferências proferidas por civis e oficiais militares. Nos dois primeiros anos, o ministro da Educação e Cultura, Jarbas Passarinho (1969-1974), proferiu a conferência de abertura. As ministradas no ano de 1973 e no período de 1975 a 1980 não foram registradas na publicação. Os 20 volumes de Cadernos de Estudos Brasileiros também não publicaram todos os textos apresentados pelos conferencistas ao longo da existência do curso, apesar de ser essa a proposta inicial. Tampouco informam o número total de alunos formados em cada edição do curso, com exceção do primeiro ano. O ano de 1978 apresenta uma situação excepcional: não se publicou nenhuma das conferências proferidas naquele ano.

Quadro 1 - Cadernos de Estudos Brasileiros

\begin{tabular}{|c|c|c|}
\hline Ano do Curso: & Número de conferências publicadas: & Número de volumes publicados: \\
\hline 1971 & 17 & 3 \\
\hline 1972 & 9 & 1 \\
\hline 1973 & 3 & 1 \\
\hline 1974 & 3 & 2 \\
\hline 1975 & 5 & 2 \\
\hline
\end{tabular}




\begin{tabular}{|c|c|c|}
\hline Ano do Curso: & Número de conferências publicadas: & Número de volumes publicados: \\
\hline 1976 & 8 & 3 \\
\hline 1977 & 5 & 1 \\
\hline 1979 & 3 & 1 \\
\hline 1980 & 2 & 2 \\
\hline
\end{tabular}

Fonte: Ministério da Educação e Cultura. Cadernos de Estudos Brasileiros. Rio de Janeiro: MEC/FENAME, 1972-1980

No caso dos militares, para proferir as palestras eram convidados oficiais de alta patente - generais, vice-almirantes e coronéis -, lotados nos ministérios ou em altos postos das agências de governo durante a ditadura civil-militar. Civis ou militares, eles eram homens de Estado, muitos dos quais filiados à Arena. O quadro 2 oferece uma análise das temáticas tratadas nas 126 conferências registradas nos Cadernos:

Quadro 2 - Conferências registradas nos Cadernos

\begin{tabular}{|c|c|c|}
\hline Temática: & $\mathrm{N}^{\circ}$ de conferências: & $\%$ \\
\hline Civismo & 5 & 6,3 \\
\hline Segurança Nacional & 8 & 10,8 \\
\hline Educação & 20 & 25,2 \\
\hline Cultura & 11 & 13,86 \\
\hline Economia & 43 & 54,18 \\
\hline Política Nacional & 7 & 8,82 \\
\hline $\begin{array}{c}\text { Geopolítica e Relações } \\
\text { Internacionais }\end{array}$ & 4 & 5,04 \\
\hline Ciências Humanas & 12 & 15,12 \\
\hline Saúde & 7 & 8,82 \\
\hline Ciência e Tecnologia & 6 & 7,56 \\
\hline Total: & 126 conferências & $100 \%$ \\
\hline
\end{tabular}

Fonte: Ministério da Educação e Cultura. Cadernos de Estudos Brasileiros. Rio de Janeiro: MEC/FENAME, 1972-1980

Mais da metade das conferências era dedicada à área de economia e, particularmente, aos temas relacionados a infraestrutura, planejamento, uso das riquezas naturais e modelos de desenvolvimento nacional. Os pontos de estrangulamento, como 
inflação, energia e transporte, também eram trabalhados pelos conferencistas. Outro tema recorrente era a necessidade de investimento nas carreiras científicas e tecnológicas no ensino superior e no ensino técnico, assim como no da educação de jovens e adultos. As demais conferências investiam nas análises sobre as possibilidades de desenvolvimento e os caminhos da segurança nacional. Em conjunto, essas conferências realçavam o caráter desenvolvimentista, o discurso anticomunista e o nacionalismo tão característicos da ditadura civil-militar, numa tentativa de construir uma narrativa totalizante sobre a sociedade brasileira. Priorizavam-se o desenvolvimento econômico e tecnológico, a cultura nacionalista e a educação para o trabalho.

Dentre as conferências publicadas nos Cadernos, destacamos a que foi proferida por Humberto Grande, diretor-executivo da Fundação Nacional do Material Escolar ${ }^{2}$ Fename -, dedicada ao conceito de civismo. O texto "O Humanismo Brasileiro", publicado em 1974, apresentava a função cívica da Fename:

Na sua programação patriótica e cultural, inspirada no humanismo cristão, a Fundação Nacional de Material Escolar, procura fortalecer o desejo de fazer grandes coisas na alma da juventude e do povo do nosso país para manter em acelerado movimento a roda do civismo nacional, a fim de que todos os cidadãos, possuídos de superior ideal, fé e muito entusiasmo, congreguem os seus esforços na realização triunfal de um Brasil Grande. (...) (GRANDE, 1974, p. 45).

A questão do civismo era compreendida pelo diretor da fundação como um ideário de valorização da cultura e da tradição nacionais, sem que isso significasse um "hiper nacionalismo" ou uma prática xenófoba. O civismo se integrava aos valores universais da civilização pelo contato saudável da cultura nacional com as práticas culturais ocidentais. Este diálogo não era considerado ameaçador, desde que fossem observadas as tradições pátrias, as especificidades nacionais e os interesses da nação. O desenvolvimento nacional dependia desse contato benéfico entre as nações ocidentais modernas e desenvolvidas.

\footnotetext{
${ }^{2}$ A FENAME foi criada através da lei 5.327, de 2 de outubro de 1967, e extinta em 1998. Sua função era produzir e distribuir material didático a preço de custo, sem fins lucrativos, favorecendo a divulgação e o uso desses materiais entre os estudantes brasileiros.
} 
A Fename foi responsável pela publicação de diversos materiais didáticos elaborados pelos intelectuais atuantes no MEC no período da ditadura civil-militar. Das obras publicadas pela fundação, selecionamos aquelas organizadas pelos intelectuais do Conselho Federal de Cultura, também idealizadores do Curso de Atualização de Estudo dos Problemas Brasileiros. Havia, neste sentido, uma circularidade na ação desses intelectuais, os quais abriram várias frentes de atuação no interior do Estado, objetivando ocupar espaços na formação, organização e difusão do pensamento conservador sobre a cultura nacional.

Outra publicação da Fename, organizada pelos intelectuais da cultura atuantes no MEC, foi o Atlas Cultural do Brasil, obra coordenada pelo presidente do Conselho Federal de Cultura - CFC -, prof. Arthur Cézar Ferreira Reis, e publicada em 1972 como parte integrante das comemorações do sesquicentenário da independência do Brasil. O cuidadoso processo de edição, perceptível pela magnitude da obra, demonstra a importância do projeto. A obra está dividida em 21 temáticas, distribuídas em 367 páginas, amplamente ilustradas: "espaço físico"; "Brasil político"; "o Homem e a Natureza”; “formação histórica”; “população brasileira”; “áreas culturais"; “falares regionais"; “criatividade popular"; "atividade científica”; “processo educacional”; “instituições culturais e sistema de comunicações"; “panorama literário"; “música”; "teatro"; “cinema”; “artes plásticas”; “arquitetura”; “rede de transportes”; “turismo”; “processo econômico"; “integração nacional”. Os artigos foram escritos por 18 autores, dos quais dez eram membros do CFC. A tentativa de popularizar a obra fixou seu preço em 60 cruzeiros.

O prefácio, escrito por Arthur Reis, resumia os objetivos concretizados pelo projeto e a função cívica e didática da obra. A primeira página do prefácio trazia a imagem da obra Monumento do Ipiranga, relevo monumental em bronze, esculpido por Ettore Ximenez em 1922, e inspirado em pintura de Pedro Américo. A escolha da imagem funcionava como um registro do ano do centenário da Independência. A próxima imagem era a gravura Prospecto da cidade de Santa Maria de Belém do Grão-Pará, datada de 1784, provavelmente escolhida por Arthur Reis (1972) em homenagem à sua região de origem, a Região Norte. No prefácio, ele (REIS, 1972, p.7) ressaltou a importância do Atlas que 
pretendia "ser um retrato autêntico do Brasil" ao promover um minucioso inventário dos aspectos culturais e físicos do País, "através dos textos, quadros estatísticos, das telas e dos mapas."

Destacava ainda a ousadia bem-sucedida do projeto ao pretender registrar as realizações efetivadas nos últimos 500 anos e que preservavam a história da "nação brasileira". Arthur Reis declarava que o maior mérito da obra era ter escapado de quaisquer demonstrações ufanistas ou pessimistas sobre a trajetória nacional. O Atlas era considerado pelos intelectuais do MEC o resultado de um realismo investigativo profundo, marcado pela neutralidade das técnicas e metodologias das ciências humanas, tornando-se o guia da formação sociocultural brasileira. Após o registro da totalidade dos eventos e obras do País e da imparcialidade da obra, Arthur Reis apresenta o conceito de cultura utilizado. O conceito defendia que as criações materiais e espirituais das sociedades surgem da relação entre os seus povos formadores e sua inter-relação com o espaço físico. Ao buscar os elementos formadores da nacionalidade, sem poder negar as grandes diferenças culturais das regiões brasileiras, o autor reafirma a estratégia do Conselho de compreender a cultura nacional como valorosamente regional, elemento da especificidade e originalidade da cultura brasileira, harmonicamente construída pela convivência pacífica dos povos aqui reunidos, sem violência, descontinuidades ou ameaças que ferissem a grandiosidade da nação.

O processo cultural, aqui compreendido como expressão de sua inteligência e como atitude em face do mundo físico de que dispõem, vem sendo um processo em que se pode encontrar, apesar da variedade regional, uma unidade real, que se consolida efetivamente nos dias de hoje pela execução mais veloz, da política de integração, que não desestimula a riqueza regional, mas vincula, mais intensamente, todo o vasto arquipélago no sentido mais forte da nacionalidade (REIS, 1972, p.10).

Para compreender os aspectos gerais da obra, selecionamos alguns capítulos considerados exemplares. O quarto capítulo, intitulado Formação Histórica, apresentava um panorama da trajetória política brasileira desde a "origem portuguesa" até a reforma da Constituição de 1967. Sob responsabilidade de Hélio Vianna, membro do CFC, a formação histórica do País era narrada privilegiando os grandes acontecimentos. O golpe 
de 1964 e os atos institucionais que marcaram a ditadura civil-militar são considerados medidas revolucionárias e emergenciais para evitar o caos provocado pela presença de elementos subversivos e alheios à nossa formação social. O texto apresentava as ações autoritárias do Executivo como as cassações de mandato e as demissões punitivas como estratégias necessárias em uma "guerra revolucionária" promovida contra os "agitadores", que utilizavam mecanismos de terror como sequestros, assaltos, atentados. O penúltimo capítulo, Processo Econômico, também descreve o desenvolvimento da economia brasileira desde os tempos coloniais até aquele momento. Para o autor, José Augusto da Silva Reis, eram inegáveis o crescimento econômico vivido pelo País naqueles anos de chumbo e seus benefícios sociais. O caráter ufanista da obra está presente nos principais textos. O último capítulo, Integração Nacional, escrito por Arthur Cezar Ferreira Reis, apresenta a "evolução histórica” do processo de interiorização caracterizado por uma política de integração iniciada na colônia com a criação das capitanias, consideradas embriões do espírito federativo, até os áureos anos da República, com a vitória do Brasil na copa do mundo de 1970 - afinal, "este esporte no país, constitui vigoroso elemento de reforço do sentimento nacional” (REIS, 1972, p. 376). O livro será encerrado com outra imagem em homenagem ao processo de Independência do Brasil: o Monumento do Ipiranga, datado de 1922, também do escultor Ettore Ximenez.

O Atlas funcionava como uma obra de referência ao projetar luz sobre o passado e apresentar os processos de mudança que forneceram ao País as estruturas necessárias à “etapa que nos afasta do subdesenvolvimento." O pioneirismo da obra era garantido pelo enfoque dos vários aspectos que formavam a nacionalidade, incluindo os aspectos geográficos, superando, conforme afirma seu organizador, as obras que faziam referência apenas às análises históricas no desenvolvimento da cultura. Contudo, a importância desse passado na construção de uma narrativa para cada temática é inegável; com exceção da primeira temática - Espaço Físico -, que ocupava 12 páginas, todos os demais tópicos buscavam reconstituir a trajetória histórica do País desde o período colonial até aquele momento. A cultura brasileira era retratada por esse viés, associada especialmente aos eventos políticos consagrados, escrita por intelectuais. Embora a maioria fosse constituída de historiadores não-profissionais, assumiam, 
entretanto, o ofício da história em busca da nacionalidade, por sua atitude cívica de resgatar os acontecimentos considerados marcantes e que pareciam estar à espera do especialista que os iria fidedignamente retratar.

Já o livro O cidadão e o civismo: educação moral e cívica, suas finalidades, organizado por Adonias Aguiar Filho, em 1982, com o financiamento da CNMC e do Instituto Nacional do Livro, através do Pró-memória, foi inteiramente dedicado ao civismo, detalhando os deveres do cidadão, a função do Estado e da sociedade civil no ensino das práticas cívicas às gerações futuras e, principalmente, a estrutura ideológica do conceito. A obra foi organizada em oito capítulos, escritos por Adonias Filho, Manoel Gonçalves Ferreira Filho, Arthur Machado Paupério, Américo Jacobina Lacombe, Pedro Calmon, padre Estevão Bittencourt, Manuel Diégues Júnior, dom Luciano José Cabral Duarte, com introdução de Ruy Vieira da Cunha.

Para Aguiar Filho (1982, p. 36), a execução das funções administrativas pelo Estado, a existência de partidos políticos representativos dos interesses coletivos, a fiscalização do judiciário, dependiam da consciência dos cidadãos de seus deveres cívicos. A ameaça das ideologias totalitaristas preconizadas pelas lideranças nazistas e comunistas só seria refutada pelas sociedades democráticas com a formação desse cidadão através de investimentos estatais na área educacional. O pleno exercício das práticas cívicas, função social prioritária do cidadão, considerado o agente conservador responsável pela preservação das estruturas sociais a partir da proteção dos valores superiores humanos, dependia da adequada formação cívica proporcionada pela educação através do Estado.

$\mathrm{E}$, precisamente porque depende do cidadão, a sociedade não tem como ignorar a sua formação educacional. [...] Mas, dentre os deveres desse cidadão educado para servir à sociedade e à família, sobressairão as atividades cívicas - concentradas no culto à Nação - que têm origens na valorização mesma do caráter nacional. [...] complexo cultural, pois, porque abrangente de todos os valores que compõem o caráter nacional, é que deve motivar as atividades cívicas do cidadão (AGUIAR FILHO, 1982, p. 36).

Para esse autor, há uma hierarquia entre os valores sociais. Os mais fundamentais são os valores superiores absolutos, quais sejam, os valores éticos e os valores cívicos. No 
ensaio, o conselheiro não detalhou quiséramos aspectos que constituíamos valores éticos, centrando-se apenas na análise dos valores cívicos. Esses "valores superiores absolutos" estavam alicerçados nos elementos nacionais formados pelos "produtos culturais da nação." A associação nação-cultura foi construída através da leitura estruturalista da cultura que a definia, na longa duração, como o conjunto de costumes, normas, tradições, crenças, território e língua, formando, ainda segundo Aguiar Filho (1982, p. 43) “[...] o complexo cultural, (que) engendra e configura o caráter nacional”. As práticas cívicas, realizadas pelos cidadãos conscientes de seus deveres na manutenção da nação, estariam apoiadas nas estruturas culturais. O civismo, por ser um valor superior absoluto, constrói um aparato simbólico igualmente absoluto, como os hinos, os heróis, as datas singulares, os mitos de origem.

Manuel Diégues Júnior propôs que o civismo é formado por três elementos também essenciais e necessários à harmonia social: a consciência nacional, a unidade nacional e a tradição nacional. A relação de interdependência entre esses elementos, geradores do civismo, é claramente apresentada. A conscientização dos cidadãos, considerados os principais agentes sociais, depende da incorporação dos "autênticos valores da nacionalidade" expressos pela cultura através da educação. Esses valores forjam o "sentimento de unidade nacional", pois refletem o espírito nacional construído desde o princípio da formação social brasileira. A tradição nacional, por sua vez, é a soma da crença na existência da unidade nacional associada à trajetória histórica comum. $\mathrm{O}$ papel da tradição é fundamental na seleção dos registros culturais que devem ser preservados. Os registros identificados pelos intelectuais como geradores estruturantes da sociedade brasileira integram a categoria de tradição nacional e reforçam o sentimento de unidade.

Cumpre ressaltar que uma verdadeira política de defesa dos valores culturais e sociais não se fará se não repousar na tradição - naquilo que, como herança de nossos antepassados, é preservado e conservado, em que pesem as possíveis modificações originais de cada época em que vive respectiva sociedade (DIÉGUES JÚNIOR, 1982, p. 116).

A ideia de civismo como elemento chave na construção da consciência nacional estava ancorada na organização de uma política de proteção do passado. Esse passado, 
compreendido como memória, era considerado o elemento-síntese da tradição nacional esta, a principal responsável por fornecer os registros da nacionalidade. Assim, o passado deveria ser cultuado pelo ensino e pela cultura. Esse culto era identificado com o patriotismo necessário à construção do imaginário social, ao estabelecimento de laços de solidariedade e à reciprocidade necessária entre o Estado e a sociedade civil.

É invariável, no tempo e no espaço, a lei de preservação da memória com base na identificação social. [...] A liga que o (povo) envolve provém da língua em que se exprime; mas para lhe dar consciência do seu ser, tem de instrumentar as reminiscências comuns. A sua solidez decorre da sua recordação. Todos dentro desse ambiente [...] se sentirão solidários na medida em que conheçam e reconheçam o antepassado, a milagrosa força originária de que se desatou a dinâmica da evolução, o feito prodigioso (fonte das epopeias vindouras) e o herói providencial (objeto de culto cívico) em cujo complexo poético vibram a emoção, a fidelidade, o entusiasmo, o orgulho ou isso que, em amplitude ou abstração, chamamos de patriotismo (CALMON, 1982, p. 87).

A história-memória teria como função social conscientizar o cidadão de seu pertencimento a um "povo", através da valorização do passado, da elaboração de uma trajetória compartilhada no "tempo e no espaço", e da invenção de heróis. A construção dessas narrativas históricas, associadas à memória nacional com a função de forjar nos cidadãos sentimentos de pertencimento que promovessem o patriotismo dos nacionais, dependia da elaboração de um discurso otimista sobre a trajetória da sociedade brasileira. Afinal, como propõe Pedro Calmon, era preciso que os cidadãos, através de um “complexo poético", gerado por narrativas que destacassem a “dinâmica da evolução”, o "feito prodigioso" e o "herói providencial", se identificassem positivamente com a nação, construindo laços de solidariedade. Só um passado verdadeiramente patriótico garantiria a inevitabilidade de nossa ascensão ao seleto grupo das grandes potências mundiais.

Os intelectuais do MEC integravam uma corrente de pensamento que atravessou, resguardando as diferenças entre os grupos e suas práticas de inserção no aparato político, os diversos setores que trabalhavam no direcionamento de políticas culturais e educacionais na ditadura civil-militar: o “otimismo". Para Fico (1997, p.27), o discurso otimista foi habilmente incorporado como política de Estado e pode ser observado nas propagandas políticas, nas políticas culturais e nas obras destinadas à educação, 
buscando reforçar no imaginário social uma ideia de Brasil como "país ordeiro”, "povo pacífico" e em processo de desenvolvimento.

A propaganda política da época procurou consolidar como tradição incontestável uma certa tendência, de fato já forte naquela ocasião, de leitura sobre o Brasil: a vinculação entre os brasileiros, e a unidade na identidade, dar-se-ia através de uma cultura brasileira, mesclada com uma promissora visão do futuro (FICO, 1997, p.24).

A elaboração de um discurso que construísse um passado comum da nação tornava a cultura nacional um instrumento preponderante para demonstrar seu desenvolvimento e atravessou diversos setores estatais. Neste sentido, a ditadura civilmilitar elaborou um conjunto de imagens com o objetivo de caracterizar a nação, a partir de ideias-força, como cultura, memória e identidade. Como afirma Carlos Fico, a ditadura civil-militar buscou uma imagem sobre o Brasil que vislumbrasse na longa duração aspectos promotores de "esperança e otimismo" (FICO, 1997, p.74).

Além das disciplinas ministradas nas escolas e universidades do País e dos materiais didáticos da Fename, projetos cívicos deveriam estimular os estudantes universitários a participar de ações sociais com o intuito de desenvolver a solidariedade social e o amor à pátria. Cabe lembrar, conforme propõe Cordeiro (2009, p. 30), que setores sociais conservadores se organizavam desde o início da década de 1960 em torno de associações cívicas, exigindo a defesa da pátria e a preservação das tradições nacionais. Dentre os diversos projetos executados pelo MEC, o projeto Capistrano de Abreu, do Conselho Federal de Cultura, e os projetos Operação Rondon e Operação Mauá, ambos organizados pela Comissão Nacional de Moral e Civismo, nos chamam a atenção pela associação direta com o tema.

Os projetos Operação Rondon e Operação Mauá, de caráter nacionalista e otimista, previam que, com o trabalho assistencialista dos universitários no interior do País, seria possível amenizar as mazelas cotidianas vivenciadas por parcelas da população economicamente menos favorecidas. Além disso, esse trabalho patriótico estimularia a devoção à pátria, a defesa do Estado nacional constituído e promoveria os valores superiores absolutos, afastando os jovens das ideologias perniciosas, como o 
comunismo, que invadiam as escolas secundárias e as universidades brasileiras. Conhecer a "realidade nacional" e estimular a cooperação social, através de intervenções assistencialistas, dissolveria a ação dos movimentos de esquerda que arrastavam para suas fileiras os cidadãos mais jovens, ameaçando a ordem social. Previa-se que as ações solidárias a serem realizadas pelos projetos Rondon e Mauá substituiriam as discussões entre os jovens sobre a questão fundiária, a concentração de renda e a falta de investimentos sociais que mantinham em condições de pobreza as camadas sociais economicamente menos favorecidas da população pela intervenção assistencialista.

As ações cívicas em favor da mocidade promovidas pelo Exército brasileiro também eram prestigiadas por intelectuais atuantes no MEC. Gilberto Freyre transmitiu ao CFC o seu entusiasmo com as Olimpíadas do Exército Nacional, realizada em Recife/PE, em 1973. Raymundo Moniz de Aragão, comungando do mesmo espírito entusiástico de Freyre, informara que os jogos não eram apenas militares, mas nacionais; afinal, deles participavam os moços chamados a servir honrosamente à sua pátria. Gilberto Freyre (1973, p. 114) ainda relatou suas melhores impressões sobre o presidente da República, Emílio Garrastazu Médici (1969-1974), impressionado com o “(...) homem severo, mas sempre acolhido com simpatia pela população".

A noção de civismo era irremediavelmente associada ao fenômeno da cidadania. É impossível investigar o projeto político que constitui o civismo sem relacioná-lo com o ideal de cidadania. Afinal, o civismo, na ditadura civil-militar, tal como investigado nesta pesquisa, dialoga com as concepções gerais sobre a cidadania, sacrificando alguns dos seus direitos em nome da preservação da nação. O ideário cívico na ditadura civil-militar foi gestado dentro dos padrões estabelecidos pelo fenômeno da cidadania; contudo, radicalizado pelo pensamento conservador e nacionalista, sobrepôs-se ao fenômeno originário. Por isso, dentro dos objetivos desta pesquisa, incorporamos a noção de cidadania apresentada por José Murilo de Carvalho, sem a pretensão de esgotar, neste momento, todos os debates sobre este fenômeno. A cidadania compreendia um conjunto de direitos civis, políticos e sociais surgidos na Europa Ocidental entre os séculos XVIII e XIX, com o advento da modernidade e com o desenvolvimento do capitalismo. Para José Murilo de Carvalho, o ideal de cidadania não era um fenômeno igualmente vivenciado por 
todos os países ocidentais que buscaram na modernidade e no capitalismo um modelo político e econômico de organização social. Por isso considerava (CARVALHO, 2007, p. 12) que "a maneira como se formaram os Estados-nação condiciona assim a construção da cidadania". O historiador descreve cada um desses direitos e a frequência com que aparecem desconectados nas sociedades em determinados períodos históricos, refletindo-se na existência de "cidadãos incompletos", ainda que o ideal de "cidadania plena" fosse amplamente almejado. Na definição de cada direito, propunha:

Direitos civis são os direitos fundamentais à vida, à liberdade, à propriedade, à igualdade perante a lei. Sua pedra de toque é a liberdade individual. É possível haver direitos civis sem direitos políticos. Estes se referem à participação do cidadão no governo da sociedade. Seu exercício é limitado a parcela da população e consiste na capacidade de fazer demonstrações políticas, de organizar partidos, de votar e ser votado. Finalmente, há os direitos sociais. [...] Eles incluem o direito à educação, ao trabalho, ao salário justo, à saúde, à aposentadoria. [...] Os direitos sociais permitem às sociedades politicamente organizadas reduzir os excessos de desigualdade produzidos pelo capitalismo e garantir um mínimo de bem-estar social para todos (CARVALHO, 2007, p. 10).

No civismo, tal como reelaborado pela ditadura civil-militar, os direitos políticos, civis e sociais dos cidadãos podiam restringir-se em favor da harmonia social e da “segurança nacional”. O conceito havia sido habilmente utilizado para redefinir a relação entre o Estado e os cidadãos, num período marcado por atos institucionais que feriam os princípios da cidadania, mas que estavam perfeitamente ajustados aos princípios do civismo. Como, neste período, a ideia de civismo se sobrepunha à de ideal de cidadania, definindo prioritariamente os deveres dos cidadãos, legitimava qualquer ação do Estado em defesa da nação.

\section{Considerações finais}

As relações estabelecidas entre os intelectuais e a política têm sido objeto de estudo recorrente em diversas áreas do meio acadêmico. A história política do papel dos intelectuais e de suas interferências nas políticas governamentais foi (re)definido por volta da década de 1970, sendo este um amplo celeiro de pesquisa para o historiador. 
Sirinelli (1996, p. 291) define os intelectuais como homens capazes de criar ou mediar processos culturais; os primeiros desenvolvem as artes, a literatura e o saber, através de suas capacidades de criação do conhecimento, enquanto os segundos difundem ou concentram o saber produzido. Como propõe o autor, esses homens não estão isolados do corpo social; ao contrário, tecem laços com a sociedade, o que lhes garante uma identidade e legitima sua posição no tecido social.

Nosso objetivo foi investigar a participação dos intelectuais na organização e sistematização de políticas públicas no interior do MEC, entre 1964 e 1985, destinadas à formação do cidadão, elemento considerado chave na construção de uma "Grande Pátria”. Para os intelectuais ligados ao MEC, sobretudo presentes no Conselho Federal de Cultura e na Comissão Nacional de Moral e Civismo, a valorização das tradições culturais e históricas nacionais era fundamental para afastar qualquer tipo de "ideologia agressiva" que ameaçasse o desenvolvimento e a segurança nacionais. Estabelecida a função política da educação e da cultura, os intelectuais do MEC passaram a organizar políticas de formação de professores e difusão do civismo através de cursos e materiais didáticos.

O Estado, na tarefa máxima de garantir o equilíbrio da nação, conferia a si próprio autoridade para responder aos que abandonavam seus deveres cívicos, aviltando os direitos políticos e as liberdades individuais desses cidadãos. O Estado utilizava-se da força necessária, justificada pela ameaça constante do inimigo interno. Os direitos civis, políticos ou sociais, propagados pela cidadania poderiam ser infringidos, pois a preservação da nação era o objetivo prioritário, superando inclusive a preservação do bem-estar dos cidadãos que nela viviam. Neste processo de radicalização do civismo, as ações repressoras, as sessões de tortura, as prisões arbitrárias podiam ser justificadas. Afinal, essas vítimas, ao não cumprirem com seus deveres cívicos, se tornavam subversivas, penalizadas com a supressão de seus direitos de cidadão pelo Estado autoritário.

Sendo superior e absoluto, o civismo era incontestável. A relação dos cidadãos com o Estado encontrava nos valores cívicos seu mediador. Mas a personagem principal na defesa dos valores nacionais era o cidadão. Ele era considerado o principal agente da propagação dos valores cívicos. Assim, o investimento em políticas que lhe ensinassem os 
seus deveres diante da nação, promovendo a "consciência cívica nacional”, era tarefa urgente da área educacional. Defender a nação contra ideologias externas, sobretudo a comunista, combater o inimigo interno e contribuir para a ordem social eram funções essenciais do bom cidadão. Era preciso conscientizá-lo também através de programas no setor cultural que enfatizassem a singularidade da nação, seus aspectos estruturais, sua organicidade. No passado histórico, encontraríamos os elementos simbólicos capazes de estruturar a nação. Tais elementos foram selecionados a partir das obras da literatura, da vida de grandes personagens exemplares, das raízes das manifestações folclóricas, do acervo documental, dos bens móveis e imóveis. A incorporação do civismo como valor máximo do exercício da cidadania garantiria a segurança nacional, fortaleceria o Estado, permitiria o acesso aos benefícios de uma sociedade tradicionalmente pacífica, ordeira e harmônica. O cidadão teria seus direitos garantidos na medida em que não ameaçasse o equilíbrio da nação; quaisquer contestações ou críticas romperiam com o padrão cívico desejado e, por isso, afetariam a estrutura social.

\section{Referências}

AARÃO REIS, Daniel. Ditadura militar, esquerdas e sociedade. Rio de Janeiro: Jorge Zahar Editor, 2000. 1. ed.

AGUIAR FILHO, Adonias (Org.). O cidadão e o civismo: educação moral e cívica, suas finalidades. São Paulo: IBRASA; Rio de Janeiro: Comissão Nacional de Moral e Civismo; Brasília: INL, Fundação Pró-Memória, 1982,p. 85-94, p.87.

BRASIL. Ministério da Educação e Cultura. Decreto-lei n. 869 , de 12 de setembro de 1969. Artigo n.2: Subsídios para currículos e programas básicos de Educação Moral e Cívica. Prescrições sobre currículos e programas básicos de Educação Moral e Cívica nos três níveis de ensino. Brasília : CNMC. 1970.

CALMON, Pedro. Os grandes fatos e os grandes homens na educação moral e cívica. In: AGUIAR FILHO, Adonias (Org.).o cidadão e o civismo: educação moral e cívica, suas finalidades. São Paulo: IBRASA; Rio de Janeiro: Comissão Nacional de Moral e Civismo; Brasília: INL, Fundação Pró-memória, 1982, p. 85-94. 
CARVALHO, José Murilo de. Cidadania no Brasil: o longo caminho. Rio de Janeiro: Civilização Brasileira, 2007. 9.ed.

CONSELHO FEDERAL DE CULTURA. Atlas cultural do Brasil. Rio de Janeiro: CFC, FENAME, 1972.

CORDEIRO, Janaína Martins. Direitas em movimento: a campanha da mulher pela democracia e ditadura no Brasil. Rio de Janeiro: FGV, 2009.

DE LUCA, TaniaRegina. A revista do Brasil: um diagnóstico para a (n)ação. São Paulo: Fundação Editora da UNESP, 1999.

DIÉGUES JÚNIOR, Manuel. Compreensão dos direitos e deveres. In: AGUIAR FILHO, Adonias (Org.).O cidadão e o civismo: educação moral e cívica, suas finalidades. São Paulo: IBRASA; Rio de Janeiro: Comissão Nacional de Moral e Civismo; Brasília: INL, Fundação Pró-memória, 1982. p. 109-118.

FICO, Calos. Reinventando o otimismo: ditadura, propaganda e imaginário social no Brasil. Rio de Janeiro: Fundação Getúlio Vargas, 1997.

GOMES, Angela Maria de Castro. República, educação cívica e história pátria: Brasil e Portugal. In: ANPUH. XXV Simpósio Nacional de História: História e Ética. Anais... Fortaleza, UFC: 2009. p.1-8.

GOMES, Angela Maria de Castro. História e historiadores. Rio de Janeiro: Fundação Getúlio Vargas, 1996.

GRANDE, Humberto Teixeira. Humanismo Brasileiro. Cadernos de Estudos Brasileiros, Rio de Janeiro: UFRJ , v.11, p.34-141, 1974.

GRINBERG, Lucia. Partido político ou bode expiatório: um estudo sobre a Aliança Renovadora Nacional (Arena), 1965-1979. Rio de Janeiro: Ed. Mauad: FAPERJ, 2009.

LABORIE, Pierre. 1940-1944:os franceses do pensar-duplo. In: ROLLEMBERG, D. e QUADRAT, S. (Orgs.). A construção social dos regimes autoritários: legitimidade, consenso e consentimento no século XX. Rio de Janeiro: Civilização Brasileira, 2010, 3v., v. 1, p.31-44.

MAIA, Tatyana de Amaral. Os cardeais da cultura nacional: O Conselho Federal de Cultura na ditadura civil-militar (1967-1975). São Paulo: Iluminuras: Instituto Itaú Cultural, 2012.

MENEZES, Djacir. Editorial. Fórum de Ciência e cultura. Cadernos de Estudos Brasileiros. Rio de Janeiro: UFRJ, v. 1, n. 1, 1972.

MINISTÉRIO DA EDUCAÇÃO E CULTURA. Cadernos de Estudos Brasileiros. Rio de Janeiro: MEC/FENAME, 1972-1980 
REIS, Arthur Cesar Ferreira. Integração Nacional. In: CONSELHO FEDERAL DE CULTURA. Atlas Cultural do Brasil. Rio de Janeiro: FENAME, 1972 p. 369-367.

REIS, Arthur Cesar Ferreira. Prefácio. In: CONSELHO FEDERAL DE CULTURA. Atlas cultural do Brasil. Rio de Janeiro: CFC/FENAME, 1972. p. 07-15.

ROLLEMBERG, Denise e QUADRAT, Samanta Viz. (Orgs.). Apresentação: A construção social dos regimes autoritários, legitimidade, consenso e consentimento no século XX. Brasil e América Latina. Rio de Janeiro: Civilização Brasileira, 2010, 3v., v. 2. p. 9-30.

SIRINELLI, Jean-François Os intelectuais. In: RÉMOND, Réne. Por uma história política. Trad. Dora Rocha. Rio de Janeiro: Editora UFRJ, 1996.

UNIVERSIDADE FEDERAL DO RIO DE JANEIRO. Cadernos de Estudos Brasileiros. Rio de Janeiro: Fórum de Ciência e Cultura/UFRJ, 1972-1980. v. 1-20

Recebido em: 03/08/2013

Aprovado em: 29/10/2013

Universidade do Estado de Santa Catarina - UDESC

Programa de Pós-Graduação em História - PPGH

Revista Tempo e Argumento

Volume 05 - Número 10 - Ano 2013

tempoeargumento@gmail.com 